\title{
Gender associated differences in determinants of quality of life in patients with COPD: a case series study Juan P de Torres* ${ }^{* 1}$, Ciro Casanova ${ }^{\dagger 1}$, Concepción Hernández ${ }^{\dagger 1}$, Juan Abreu ${ }^{\dagger 1}$, Angela Montejo de Garcini ${ }^{\dagger 1}$, Armando Aguirre-Jaime ${ }^{\dagger 1}$ and Bartolome R Celli ${ }^{\dagger 2}$
}

Address: ${ }^{1}$ Respiratory Research Unit, Hospital Nuestra Sra de Candelaria, Tenerife, Spain and ${ }^{2}$ Pulmonary and Critical Care Division, St. Elizabeth's Medical Center, Boston, USA

Email: Juan P de Torres* - jupa65@hotmail.com; Ciro Casanova - ccasanova@canarias.org; Concepción Hernández - chernandez@teleline.es; Juan Abreu - juan_abre@hotmail.com; Angela Montejo de Garcini - amontejo@hotmail.com; Armando Aguirre-Jaime - aaguirre@canarias.org; Bartolome R Celli - bcelli@copdnet.org

* Corresponding author †Equal contributors

Published: 28 September 2006

Health and Quality of Life Outcomes 2006, 4:72 doi:10.1 186/1477-7525-4-72
Received: 19 July 2006

Accepted: 28 September 2006

This article is available from: http://www.hqlo.com/content/4/I/72

(C) 2006 de Torres et al; licensee BioMed Central Ltd.

This is an Open Access article distributed under the terms of the Creative Commons Attribution License (http://creativecommons.org/licenses/by/2.0), which permits unrestricted use, distribution, and reproduction in any medium, provided the original work is properly cited.

\begin{abstract}
Background: The influence of gender on the expression of COPD has received limited attention. Quality of Life (QoL) has become an important outcome in COPD patients. The aim of our study was to explore factors contributing to gender differences in Quality of Life of COPD patients.
\end{abstract}

Methods: In 146 men and women with COPD from a pulmonary clinic we measured: Saint George's Respiratory Questionnaire (SGRQ), age, smoking history, $\mathrm{PaO}_{2}, \mathrm{PaCO}_{2}, \mathrm{FEV}$, $\mathrm{FVC}, \mathrm{ICl}$ TLC, FRC, body mass index (BMI), 6 minute walk distance (6MWD), dyspnea (modified MRC), degree of comorbidity (Charlson index) and exacerbations in the previous year. We explored differences between genders using Mann-Whitney U-rank test. To investigate the main determinants of QoL, a multiple lineal regression analysis was performed using backward Wald's criteria, with those variables that significantly correlated with SGRQ total scores.

Results: Compared with men, women had worse scores in all domains of the SGRQ (total 38 vs $26, p=0.01$, symptoms 48 vs $39, p=0.03$, activity 53 vs $37, p=0.02$, impact 28 vs $15, p=0.01$ ). SGRQ total scores correlated in men with: FEV $\%(-0.378, p<0.001), I C / T L C(-0.368, p=0.002)$, $\mathrm{PaO}_{2}(-0.379, \mathrm{p}=0.00 \mathrm{I}), \mathrm{PaCO}_{2}(0.256, \mathrm{p}=0.05), 6 \mathrm{MWD}(-0.327, \mathrm{p}=0.005)$, exacerbations $(0.366$, $\mathrm{p}=0.00 \mathrm{I})$, Charlson index $(0.380, \mathrm{p}=0.00 \mathrm{I})$ and MMRC $(0.654, \mathrm{p}<0.00 \mathrm{I})$. In women, the scores correlated only with $\mathrm{FEV}_{1} \%(-0.293, \mathrm{p}=0.013) \mathrm{PaO}_{2}(-0.315, \mathrm{p}=0.007)$, exacerbations $(0.290, \mathrm{p}=$ $0.013)$ and MMRC $(0.628, \mathrm{p}<0.00 \mathrm{I})$. Regression analysis $(\mathrm{B}, 95 \% \mathrm{Cl})$ showed that exercise capacity $(0.05,0.02$ to 0.09$)$, dyspnea $(17.6,13.4$ to 21.8$)$, IC/TLC (-5I.I, -98.9 to -3.2$)$ and comorbidity (I.7, 0.84 to 2.53$)$ for men and dyspnea $(9.7,7.3$ to I 2.4$)$ and oxygenation $(-0.3,-0.6$ to -0.0 I) for women manifested the highest independent associations with SGRQ scores.

Conclusion: In moderate to severe COPD patients attending a pulmonary clinic, there are gender differences in health status scores. In turn, the clinical and physiological variables independently associated with those scores differed in men and women. Attention should be paid to the determinants of QoL scores in women with COPD. 


\section{Background}

Chronic Obstructive Pulmonary Disease (COPD) primarily affects the airway and lung parenchyma while it also induces clinically important systemic consequences. For an appropriate diagnosis and follow up a multidimensional evaluation of the disease is required including: degree of airway obstruction, lung hyperinflation, dyspnea, exercise capacity, quality of life and nutritional status.

The influence of gender on the clinical expression of COPD has received limited attention. The lack of information regarding gender and COPD is surprising, because according to the recent COPD disease surveillance in the United States [1], for the first time in 2002, the number of women dying from this disease surpassed that of men.

Quality of Life has become an important measurable outcome in patients with Chronic Obstructive Pulmonary Disease (COPD). It is known to predict mortality [2], hospitalization [3], health care resource utilization [3] and response to different treatment options [4]. The Saint George's Respiratory Questionnaire (SGRQ) has become one of the most widely used health-related specific questionnaires for assessing QoL in respiratory patients [5].

In the literature there are few reports suggesting a greater impairment in health related quality of life in female patients with COPD [6-10]. Several studies completed mainly in men with COPD, have explored the physiological and psychological factors associated with QoL impairment [11-14]. They have shown that dyspnea, six minute walk distance (6MWD), $\mathrm{PaO}_{2}, \mathrm{FEV}_{1}$, anxiety and depression are associated with the QoL scores in these patients.

In a previous study [15], we found that in a $\mathrm{FEV}_{1} \%$ matched population of COPD patients, women had worse SGRQ scores than men at younger age and earlier stage of the disease. We planned the present study in a larger sample, to explore possible gender differences in the factors associated and predictive of SGRQ scores in both genders.

\section{Methods}

This $\mathrm{FEV}_{1}$ matched case series study, recruited COPD patients attending the pulmonary clinic at Hospital Universitario Ntra Sra de Candelaria, a tertiary public university hospital in Spain from January 2000 to December 2005. We recruited 73 consecutive women attending the clinic and then matched 73 patients with similar degree of airflow obstruction randomly selected from our much larger population of men with COPD. Patients with all degree of airflow severity were included if they had smoked $\geq 20$ pack years and had a post-bronchodilator $\mathrm{FEV}_{1} / \mathrm{FVC}$ of $<0.7$ after 400 micrograms of inhaled albuterol. Patients were excluded if they had a history of asthma, has a history of bronchiectasis, tuberculosis or other confounding diseases. The patients were clinically stable (no exacerbation for at least 2 months) at the time of the evaluation and were part of the population studied for the BODE international multicenter study [16]. The Ethical Committee of the Hospital approved the study and all patients signed the informed consent.

We evaluated the QoL of the study sample by the SGRQ. We also measured proven prognostic parameters for COPD patients: age, degree of airflow obstruction by $\mathrm{FEV}_{1}$, dyspnea by the Modified Medical Research Council scale (MMRC), exercise capacity by the Six Minute Walk Distance (6MWD) and the presence of comorbidities by the combined Charlson index [17] where the higher the score, the more co-morbidities are present, and the exacerbations in the previous year of the study date.

Postbronchodilator $\mathrm{FEV}_{1}, \mathrm{FVC}, \mathrm{FEV}_{1} / \mathrm{FVC}$ and IC/TLC were determined taking the European Community for Steel and Coal for Spain reference [16] using a Jaegger 920 MasterLab ${ }^{\circledast}$ Body Box. BMI was calculated as the weight in kilograms divided by height in meters ${ }^{2}$. Arterial blood gases were measured at rest.

Exacerbations were defined as episodes of increased dysnea, production of phlegm and cough that required medical attention, differentiating those that required admission and those that did not for one full year.

The 6MWD was performed following the ATS guidelines [19] using as reference values those of Troosters et al [18]. Functional dyspnea was measured using the ATS modified MMRC [21]. Health status was determined using the language-specific validated SGRQ questionnaire that provides three individual domain scores: symptoms, activity, impact (psychosocial dysfunction). A total score is calculated, with zero indicating no impairment and 100 representing maximum impairment [5].

We used the following gender matching method: from an initial sample of 110 males and 73 females with COPD; we were able to match every female patient with a male with $\mathrm{FEV}_{1} \%$ of predicted $\pm 2 \%$; when more than one male matched, we chose the male patient to be included in the final sample by random drawing from a list while being blinded to the rest of the parameters included in this study. The matching process was done prospectively and at the time of diagnosis. A sample of 73 patients in each group allowed us to detect a relevant difference as small as 10 points for SGRQ scores, in a two-tailed test at 5\% significant level with a power of $85 \%$, considering a median SGRQ value of 30 points for men and 40 for women. 
We describe each variable using mean $\pm \mathrm{SD}$ or median ( $25^{\text {th }}$ percentile- $75^{\text {th }}$ percentile) depending on their distribution. We explored for differences between genders in each parameter using Student t-test for variables with approximately normal distribution, Mann-Whitney Urank test for variables without normal distribution. We then correlate SGRQ Total scores with the different studied variables. A multiple linear regression analysis was performed using backward Wald's criteria, with those variables that significantly correlated with SGRQ Total scores. A p value $\leq 0.05$ was considered statistically significant.

\section{Results}

The patients were white Caucasian and when enrolled, $25 \%$ of the men and $23 \%$ of the women were still smoking. None of the patients had a history of exposure to biomass fuel. Using the GOLD staging system [22] we have equal number of men and women in each GOLD Stage (I 13\%, II 43\%, III 36\%, IV 5\%).

The clinical and physiological characteristics of the patients participating in the study are described in Table 1. Women were younger and smoked less than men. There were no differences in current smoking status. Women had lower BMI and a higher percentage of them had a BMI $\leq 21$. Women had less co-morbidities and more exacerbations in the previous year than men. No differences were found in FRC\% predicted. Women had a higher $\mathrm{PaO}_{2}$ and lower $\mathrm{PaCO}_{2}$ than men. Even though they had the same predicted $\mathrm{FEV}_{1}$ and better mean $\mathrm{PaO}_{2}$, women had a lower $6 \mathrm{MWD}$ in \% of predicted values and reported more functional dyspnea. They also scored worse in all domains of the SGRQ.

When we compared SGRQ scores for the population divided by $\mathrm{FEV}_{1} \%$ in greater and lower than $50 \%$, there were gender differences only for the group with $\mathrm{FEV}_{1}$ $>50 \%$ group [ $\mathrm{n}=43$ for each gender, $\mathrm{p}<0.05$ in all comparisons, men and women respectively: total $17(6-30)$ vs 32 (25-42), symptoms $31(11-44)$ vs $42(28-56)$, activity $23(8-40)$ vs $53(43-56)$ and impact $8(5-26)$ vs 20 (13$35)]$. We did not find differences for the more severe group of patients (FEV1\% $<50 \%$, GOLD stages III and IV).

Those parameters that significantly correlated with SGRQ total scores are shown in Table 2 for the entire population and divided by gender. There were gender differences in the parameters that correlated with SGRQ.

Table 3 shows multiple linear regressions of those factors that significantly correlated with SGRQ Total scores divided by gender. Once again, the factors that predict SGRQ total scores differed by gender. Figure 1 shows the relative weight of the studied factors retained in the multiple linear logistic regression analysis as predictors of the

Table I: Comparisons of clinical and physiological characteristics between women and men matched by their predicted FEV,

\begin{tabular}{|c|c|c|c|}
\hline Clinical \& Physiological Characteristics & Men $(n=73)$ & Women $(n=73)$ & p Value \\
\hline Age (years old) & $63 \pm 8^{*}$ & $56 \pm 11 *$ & $<0.001$ \\
\hline Age range & 47-77 & 37-79 & \\
\hline Pack-years history & $69 \pm 26^{*}$ & $47 \pm 22^{*}$ & $<0.001$ \\
\hline BMI $\left(\mathrm{kg} / \mathrm{m}^{2}\right)$ & $27 \pm 4^{*}$ & $25 \pm 7 *$ & 0.04 \\
\hline $\mathrm{BMI} \leq 2 \mathrm{I}(\%)$ & 6 & 32 & 0.007 \\
\hline Charlson Index (points) & $3(1-6)+$ & $I(I-3)+$ & $<0.001$ \\
\hline \multicolumn{4}{|l|}{ MMRC (points) } \\
\hline $0-2(\%)$ & 93 & 71 & $<0.001$ \\
\hline $3-4(\%)$ & 7 & 29 & \\
\hline \multicolumn{4}{|l|}{ Exacerbations in the last year } \\
\hline Without admission & $0(0-1)+$ & $I(0-2)+$ & 0.013 \\
\hline With admission & $0(0-0)+$ & $0(0-1)+$ & 0.116 \\
\hline FRC $\%$ of predicted & $|42 \pm 3|^{*}$ & $134 \pm 32 *$ & 0.470 \\
\hline IC/TLC $\leq 0.25(\%)$ & $8(\mathrm{II})$ & $7(10)$ & 0.627 \\
\hline $\mathrm{PaO}_{2}(\mathrm{mmHg})$ & $70 \pm 11 *$ & $76 \pm 11 *$ & 0.004 \\
\hline $\mathrm{PaCO}_{2}(\mathrm{mmHg})$ & $45 \pm 6^{*}$ & $40 \pm 5^{*}$ & $<0.001$ \\
\hline 6MWD (mts) & $529 \pm 93 *$ & $459 \pm 79 *$ & $<0.001$ \\
\hline 6MWD \% of Predictive & $107 \pm 21^{*}$ & $85 \pm 17^{*}$ & $<0.05$ \\
\hline \multicolumn{4}{|l|}{ SGRQ } \\
\hline Total & $26(15-52)+$ & $38(30-47)+$ & 0.011 \\
\hline Symptoms & $39(12-53)+$ & $48(32-58)+$ & 0.028 \\
\hline Activity & $37(14-62)+$ & $53(40-62)+$ & 0.020 \\
\hline Impact & $15(6-45)+$ & $28(13-40)+$ & 0.013 \\
\hline
\end{tabular}

*represents mean $\pm S D ;+$ represents median and $25^{\text {th }}-75^{\text {th }}$ percentiles 
Table 2: Studied parameters that significantly correlated with SGRQ total scores.

\begin{tabular}{|c|c|c|c|}
\hline Studied parameters & Entire population & Male & Females \\
\hline $\mathrm{FEV}_{1} \%$ of predictive & $-0.378(p<0.001)$ & $-0.479(p<0.001)$ & $-0.293(p=0.013)$ \\
\hline IC/TLC & $-0.306(p=0.001)$ & $-0.368(p=0.002)$ & NS \\
\hline $\mathrm{PaO}_{2}(\mathrm{mmHg})$ & $-0.269(p=0.001)$ & $-0.379(p=0.001)$ & $-0.315(p=0.007)$ \\
\hline $\mathrm{PaCO}_{2}(\mathrm{mmHg})$ & NS & $0.256(p=0.057)$ & NS \\
\hline 6MWD (mts) & $0.267(0.002)$ & $-0.327(p=0.005)$ & NS \\
\hline Exacerbations & $0.343(p<0.001)$ & $0.366(p=0.001)$ & $0.290(p=0.013)$ \\
\hline Charlson Index & $0.210(p=0.012)$ & $0.380(p=0.001)$ & NS \\
\hline MMRC (points) & $0.659(p<0.001)$ & $0.654(\mathrm{p}<0.001)$ & $0.628(p<0.001)$ \\
\hline
\end{tabular}

We show correlation coefficients and $\mathrm{p}$ values for those that showed statistical significant correlation

Spearman's coefficients for all correlations

SGRQ total scores for male and female COPD patients. We used the $\beta$ coefficients of the parameters retained in the regression model to calculate de proportional weight that each has to predict the variance of the SGRQ total score.

\section{Discussion}

The most important finding of this study is that in moderate to severe COPD patients attending a pulmonary clinic the factors associated with SGRQ total score are different in men and women. Whereas dyspnea, exercise capacity, degree of hyperinflation and comorbidity show an independent association with the scores in men, only dyspnea and level of arterial oxygenation contributed to the score in women.

The information about gender differences in QoL of patients with COPD is scarce [6-10]. Osman et al included 266 severe COPD (123 men, 115 women) to investigate if QoL (measured by the SGRQ) could predict hospital readmission. Even though this was not an $\mathrm{FEV}_{1}$ matched population and comparison of gender differences was not the main goal of the study, they noted worse scores in women than in men. Leidy et al compared the functional performance of 45 women and 44 men with COPD using the Sickness Impact Profile. They reported no significant differences in all categories but indicated gender differences in models of functional performance. Larson and co-workers also reported worse QoL scores in women. Rodrigue et al [9] showed that in a population of COPD who underwent lung transplantation, women reported worse scores and less improvement in QoL after surgery although they had a greater improvement in their spirometric values. Recently Di Marco et al [10] reported in a population of 202 COPD patients, worse symptomrelated QoL, and more anxiety and depressive symptoms in female patients compared with men. However, all of these authors did not match for degree of airflow limitation and they did not explore differences in the factors that could help explain the worse scores in women.

As an extension to our previous published study [15], we planned this study to investigate the possible factors associated to this gender differences. We observed that SGRQ scores in all domains were higher in female patients than men. The gender differences were all higher than the 4 points considered clinically significant for SGRQ [23]. Surprisingly, when we classified the patients by severity of obstruction into $\mathrm{FEV}_{1} \%$ greater and lower than $50 \%$, only women with mild to moderate disease (GOLD stages II and II) had higher (worse) scores in all domains of the SGRQ, than the men. There were no differences in any domain for Stage III and IV patients.

This is an interesting finding considering that female with $\mathrm{FEV}_{1} \%<50 \%$ were younger than males (53 \pm 9 vs. $66 \pm 8$,

Table 3: Multiple lineal regressions with parameters that significantly correlated with SGRQ total

\begin{tabular}{|c|c|c|c|c|}
\hline Quality of Life & Group & Parameter & B (95\%Cl) & p value \\
\hline \multirow[t]{8}{*}{ SGRQ total } & Entire population $r^{2}=0.52$ & Charlson & $1.63(0.89-2.37)$ & $<0.001$ \\
\hline & & MMRC & $14.6(\mid 1.7,17.4)$ & $<0.001$ \\
\hline & Males $r^{2}=0.87$ & Charlson & $\mathrm{I} .68(0.84,2.53)$ & $<0.001$ \\
\hline & & IC/TLC & $-51.1(-98.9,-3.2)$ & 0.037 \\
\hline & & MMRC & $17.6(|3.4-2| .8)$ & $<0.001$ \\
\hline & & 6MWD & $0.05(0.02-0.09)$ & 0.002 \\
\hline & Females $r^{2}=0.48$ & MMRC & $9.7(7.3-12.4)$ & $<0.001$ \\
\hline & & $\mathrm{PaO}_{2}$ & $-0.3(-0.6,-0.01)$ & 0.042 \\
\hline
\end{tabular}




\section{SGRQ Total Score}
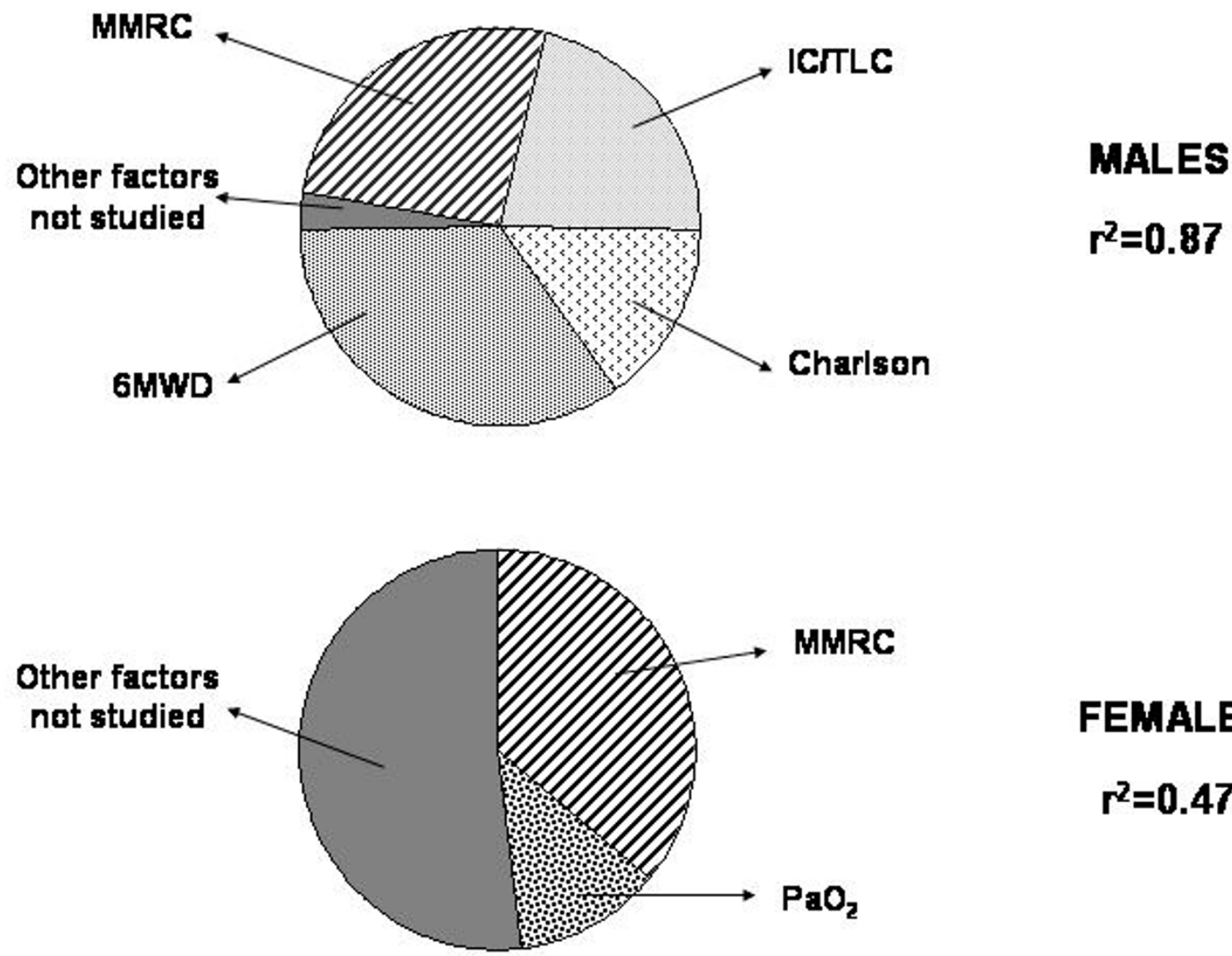

FEMALES

$r^{2}=0.47$

\section{Figure I}

The diagrams shows the relative weight of the factors retained in the logistic regression analysis as predictors of the SGRQ total scores for male and female COPD patients. SGRQ total = Saint George's Respiratory Questionaire total score. MMRC = Modified Medical Research Council scale. $6 \mathrm{MWD}=$ Six minute walking distance test. Charlson $=\mathrm{Charlson}$ index. $\mathrm{IC} / \mathrm{TLC}=$ Inspiratory Capacity/Total Lung Capacity ratio. $\mathrm{PaO}_{2}=$ Arterial oxygen pressure.

$\mathrm{p}<.001)$. We interpreted this observation as indicating that women with COPD develop symptoms influencing the SGRQ questionnaire at a younger age and with less degree of obstruction than men. Classically, we know that QoL impairment starts to be noticed when $\mathrm{FEV}_{1} \%$ falls below 50\% [24]. Our findings imply that females with COPD differ from males in having an earlier repercussion of the disease (even at predicted $\mathrm{FEV}_{1}$ values between $65-$ $80 \%$ ). This suggests that we should pay more attention to the early detection of the disease in women. Indeed, the early age of onset of impairment in QoL in women should raise alarm considering that most of the primary care physicians do not think in COPD when they see females with typical symptoms of cough, phlegm or dyspnea [25]. It is also important since the impairment of QoL in female could run for longer time and the response to different treatment options aimed at improving QoL, like pulmonary rehabilitation, are not the same in females and males with COPD [26].

In this study we also show that the variables that correlated with SGRQ scores differed by gender (Table 2). If we only consider the SGRQ total score as a summary of the QoL expression, the parameters that correlated in men $\left(\mathrm{FEV}_{1}, \mathrm{IC} / \mathrm{TLC}, \mathrm{PaO}_{2}, \mathrm{PaCO}_{2}\right.$, exacerbations, Charlson, 6MWD and MMRC) were different from those in women 
$\left(\mathrm{FEV}_{1}, \mathrm{PaO}_{2}\right.$, exacerbations and MMRC). Our results are in-line with those reported by Tsukino et al [9] in a predominatly male COPD cohort, which provides external validity to our findings. We then can speculate that the factors affecting QoL differ by gender at least in the early stages of the disease and that the perceived expression of the disease is different between genders.

Table 3 summarizes the associated predictors of SGRQ total scores for males and females with COPD with the same degree of airway obstruction. The difference between genders constitutes the most important finding of our work. While factors like dyspnea, exercise capacity, degree of hiperinflation and comorbidities explain almost $90 \%$ of the variation of the SGRQ total score in our male patients, dyspnea and level of arterial oxygenation only explained $50 \%$ of the variation of it in the female population. It suggests that the female COPD population is entirely different and that we should look for possible factors to be included in their regular evaluation to try to explain the greater and earlier impairment of their QoL.

Dyspnea continues to be the most important driving force of the QoL impairment in patients with COPD and therapies aiming at relieving this cardinal symptom are important in COPD women as well as the close follow up of their degree of arterial oxygenation. We know that psychological factors have an important impact in QoL of COPD patients [13], with a higher prevalence of depression and anxiety in female COPD patients [10]. We also know from previous works that female coping mechanisms with COPD are different that those from males [7]. We then especulate, as also recently suggested by Di Marco et al [10] that the evaluation of factors like the psychological or socio-cultural ones are possible venues that should be investigated in the female COPD population in order to explain their impaired QoL.

We believe our study has several limitations. First, our patients were recruited from those attending a pulmonary clinic and therefore may not represent the COPD population at large. Second, our findings in women may only be applicable to patients with cigarette related COPD and not to patients with COPD due to biomass fuel [27]. Third, we did not include depression and anxiety evaluations in the parameters considered, because the study was designed to explored physiologic factors previously associated with health-related quality of life in patients with COPD. Also, we also did not include generic questionnaires like the SF-36, in the evaluation of the QoL of these patients, as some investigators believe are complementary of the specific ones. Considering the scarce information in the area of QoL in women with COPD, it would have been important to include them to better reflect all aspects of the QoL impairment. Lastly, our population study mainly represents GOLD stages II and III and conclusions can only be referred to this degree of obstruction. Nevertheless, the main differences found in SGRQ scores are in the early stages of the disease, and we believe the conclusions here found represent an important message because most of the patients seen at pulmonary clinics have similar characteristics as ours.

\section{Conclusion}

In summary, our study shows that factors associated with QoL of moderate to severe COPD patients differ by gender. The main predictors of SGRQ total score in men are dyspnea, exercise capacity, degree of hyperinflation and comorbidity, whereas for women, the main predictors are dyspnea and level of arterial oxygenation. Most importantly, our data suggests that to appropiately evaluate $\mathrm{QoL}$ in women with COPD, prognostic factors other than the traditional ones should be included because these do not fully predict the health related quality of life scores.

\section{Competing interests}

The author(s) declare that they have no competing interests.

\section{Authors' contributions}

JdT conceived of the study, and participated in its design and coordination and helped to draft the manuscript. CC participated in the study design and coordination and helped to draft the manuscript. $\mathrm{CH}$ participated in the study design and coordination and helped to draft the manuscript. JA participated in the study design and coordination and helped to draft the manuscript. AM participated performing lung function test and the GMWD. AAJ helped in the design of the study and the statistical analysis of the data. BC helped in the interpretation of the data and to draft the manuscript.

\section{Acknowledgements}

We would like to acknowledge Jesus Villar MD. for his invaluable contribution in the completion of this project.

\section{References}

I. Mannino DM, Homa DM, Akinbami LJ, Ford ES, Redd SC: Chronic Pulmonary Disease Surveillance-United States, I97|-2000. MMWR Surveill Summ 2002, 5 I : I-I6.

2. Domingo-Salvany A, Lamarca R, Ferrer M, García-Aymerich J, Alonso J, Felez M, Khalaf A, Marrades RM, Monso E, Serra-Batlles J, Anto JM: Health-related quality of life and mortality in male patients with chronic obstructive pulmonary disease. Am J Respir Crit Care Med 2002, I 66:680-685

3. Sprenkle MD, Niewoehner DE, Nelson DB, Nichol KL: The veterans Short Form is predictive of mortality and health-care utilization in a population of veterans with a self reported diagnosis of asthma or COPD. Chest 2004, I 26:8I-89.

4. Jones PW: Issues Concerning Health-Related Quality of Life in COPD. Chest 1995, 107:187-193S.

5. Ferrer M, Alonso J, Prieto L, Plaza V, Monso E, marrades R, Aguar MC, Khalaf A, Anto JM: Validity and realiability of the Spanish version of the St George's Respiratory Questionnaire. Eur Respir J 1996, 9: I 160-I I66. 
6. Osman LM, Godden DJ, Friend JAR, Legge JS, Douglas JG: Quality of life and hospital re-admission in patients with chronic obstructive pulmonary disease. Thorax 1997, 52:67-7|.

7. Leidy NK, Traver G: Psychophysiologic factors contributing to functional performance in people with COPD: are there gender differences? Res Nurs Health 1995, 18:535-546.

8. Larson J, Kirchgessner J, McCutcheon J: Quality of Life in chronic obstructive pulmonary disease: Gender differences. Am J Respir Crit Care Med 1998, I57:A869.

9. Rodrigue JR, Baz MA: Are there sex differences in the healthrealated quality of life after lung transplantation for chronic obstructive pulmonary disease? J Heart Lung Transplant 2006, 25: $120-125$

10. Di Marco F, Verga M, Reggente M, Maria Casanova F, Santus P, Blasi $F$, Allegra L, Centanni S: Anxiety and depression in COPD patients: The roles of gender and disease severity. Respir Med 2006, 100:1767-1774.

II. Tsukino M, Nishimura K, Ikeda A, Koyama H, Mishima M, Izumi T: Physiologyc factors that determine the Health-Related Quality of Life in patients with COPD. Chest 1996, I 1 0:896-903.

12. Gudmundsson G, Gislason T, Janson C, Lindberg E, Suppli Ulrik C, Brondum E, Nieminen MM, Aine T, Hallin R, Bakke P: Depression, anxiety and health status after hospitalization for COPD: $A$ multicenter study in the Nordic countries. Respir Med 2006, 100:87-93.

13. Hajiro T, Nishimura K, Tsukino M, Ikeda A, Koyama H, Izumi T: Comparison of discriminative properties among diseasespecific questionnaires for measuring health-related quality of life in patients with chronic obstructive pulmonary disease. Am J Respir Crit Care Med 1998, 157:785-790.

14. Schlecht NF, Schwartzman K, Bourbeau J: Dyspnea as clinical indicator in patients with chronic obstructive pulmonary disease. Chron Respir Dis 2005, 2: 183-191.

15. de Torres JP, Casanova C, Hernandez C, Abreu J, Aguirre-Jaime A, Celli BR: Gender and COPD in patients attending a pulmonary clinic. Chest 2005, I 28:20I2-2016.

16. Celli BR, Cote CG, Marin JM, Casanova C, Montes de Oca M, Mendez RA, Pinto Plata V, Cabral HJ: The body mass index, airflow obstruction, dyspnea and exercise capacity index in chronic obstructive pulmonary disease. N Engl J Med 2004, 350:1005-1012.

17. Charlson M, Szatrowsky T, Peterson J, Gold J: Validation of a combined comorbility index. J Clin Epidemiol 1994, 47: I245-I 25 I.

18. Quanjer $\mathrm{PH}$ : Standarized lung function testing. Report of the Working Party for the European Community for Steel and Coal. Bull Eur Physiopathol Respir 1983, 19:S22-27.

19. ATS Committee on Proficiency Standards for Clinical Pulmonary Function Laboratories: ATS statement: Guidelines for the SixMinute Walk Test. Am J Respir Crit Care Med 2002, I66: I I I- I I7.

20. Troosters T, Gosselink R, Decramer M: Six minute walking distance in healthy elderly subjects. Eur Respir J 1999, 14:270-274.

21. Brooks SM: Surveillance for respiratory hazards. ATS News 1982, 8:12-16.

22. Pauwels RA, Buist AS, Calverley PM, Jenkins CR, Hurd SS, the GOLD Scientific Committee: Global strategy for the diagnosis, management, and prevention of chronic obstructive pulmonary disease. NHLBI/WHO Global Initiative for Chronic Obstructive Lung Disease (GOLD) Workshop summary. Am J Respir Crit Care Med 200I, 163:1256-1276.

23. Schunemann HJ, Griffith L, Jaeschke R, Goldstein R, Stubbing D, Guyatt $\mathrm{GH}$ : Evaluation of the minimal important difference for the feeling thermometer and the St. George's Respiratory Questionnaire in patients with airflow obstruction. J Clin Epidemiol 2003, 56:1 I70-1176.

24. Jones PW: Quality of life measurement for patients with diseases of the airways. Thorax 1991, 46:676-682.

25. Chapman KR, Tashkin DP, Pye D: Gender Bias in the Diagnosis of COPD. Chest 200I, I 19:1691-1695.

26. Foy CG, Rejeski J, Berry MJ, Zaccaro D, Woodard CM: Gender moderates the effects of exercise therapy on health-related quality of life among COPD patients. Chest 200I, I I 9:70-76

27. Dennis RJ, Maldonado D, Norman S, Baena E, Martinez G: Woodsmoke exposure and risk for obstructive airway disease among women. Chest 1996, 109:115-119.

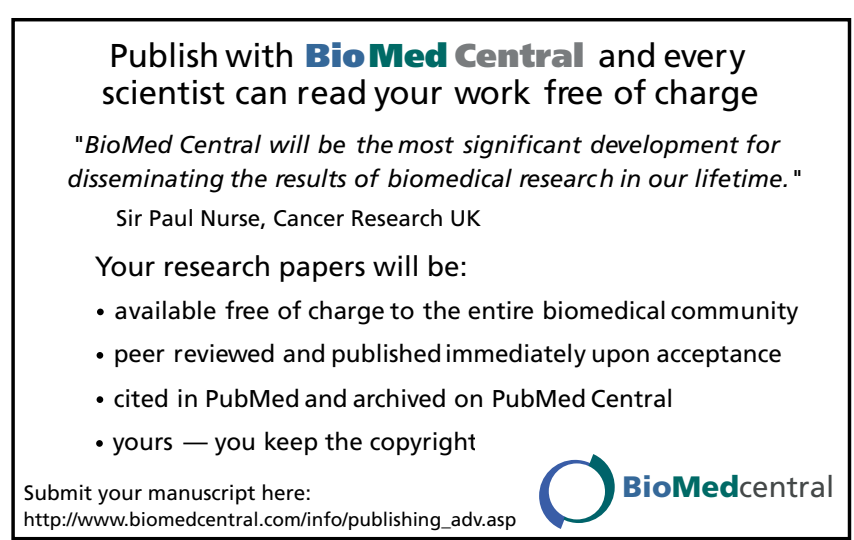

